\title{
UROGENITAL MYIASIS DUE TO CHRYSOMYIA BEZZIANA
}

\author{
*V Wadhwa, P Kharbanda, S Rai, B Uppal
}

\begin{abstract}
Genitourinary myiasis, associated with ulcerating lesions and poor hygiene of the local site, has been infrequently reported. We report a case of 45 year-old urinary incontinent female suffering from carcinoma cervix, who presented with genitourinary myiasis. The larva was identified as of Chrysomyia bezziana Villeneuve (C. bezziana).
\end{abstract}

Key words: Genitourinary myiasis, Chrysomyia bezziana

Myiasis, defined as infestation of vertebrate animals with dipterous larvae, can cause massive destruction in neglected patients accompanied by marked inflammatory reactions and secondary bacterial infections. Cutaneous myiasis is the most common form. Genitourinary involvement is rare and usually presents as pruritus and pain at the site of infection. ${ }^{1}$

Chrysomyia has been reported to cause myiasis in manand domestic animals in the tropics. Species implicated are C.bezziana(most common and the only known obligatory agent of myiasis), C.megacephala and C.rufifacies. ${ }^{2}$ The present case is of genitourinary myiasis caused by larvae of Old World screw-worm fly C. bezziana.

\section{Case Report}

A 45 year-old female, belonging to a poor family, residing in suburban area of Delhi, reported to the radiotherapy out patient department (OPD) of a tertiary care hospital in NewDelhi, India with complaints of pruritus and gnawing pain in the periuretheral area since two days. Before visiting the clinic, she was able to manually remove a small organism from the uretheral orifice, which alleviated the pain. The patient was suffering from carcinoma cervix (grade III), since two years. Three weeeks back, she developed urinary incontinence, due to the spread of the malignancy and since then had been living in poor sanitary conditions.

The organism received in the laboratory was white, measured $5 \mathrm{~mm}$ in length and had tough but not sclerotic integument. It was mounted in chloral - gum medium and kept over a hot plate (for clearing) for a week. A subsequent examination of the urine and stool sample of the patient did not reveal any pathogen. The patient was advised to attend to the gynaecology OPD for physical examination, management of urinary incontinence and antibiotic treatment. The patient could not be followed up.

*Corresponding author (e-mail: <vishal2870@yahoo.com>) Department of Microbiology, Maulana Azad Medical College \& LN Hospital, New Delhi-110 002, India

Received: 01-04-05

Accepted: 14-05-05
On microscopic examination, the body consisted of eleven apparent segments. All the segments had belts of well developed minute black spines except the anal segment. Anterior spiracle showed five finger like processes. The paired posterior spiracle situated in the cleft on the posterior face of the anal segment had three straight slit-like openings with lateral swellings and a dark peritreme surrounding them (Figure). The peritreme was incomplete enclosing the poorly defined button.

The larva was identified to genus Chrysomyia based on characteristics of the mature larva and patterns of the posterior spiracle. The five finger like processes of the anterior spiracle helped differentiate it from $C$. megacephala, which has more than five processes. ${ }^{3}$

\section{Discussion}

Myiasis, a parasitic disease of humans and vertebrates, is caused by the larvae of more than 50 fly species. Genitourinary myiasis is usually associated with poor general health and hygiene, restricted mobility, urinary obstruction and ulcerating lesions. ${ }^{4}$

Commonly implicated dipterous families include: Muscidae, Sarcophagidae, Calliphoridae, Anisopodidae and Scinoinidae. Larvae of C. bezziana (Diptera: Calliphoridae) cause obligatory myiasis producing parasites of animals and humans. Infestation is common in tropical countries, especially India..$^{5-7}$ The sites commonly involved are nose $(81 \%)$, ear (11\%), tracheostomy wound $(5 \%)$, face $(1 \%)$, gums and serous cavities (1\%). ${ }^{8}$ Genitourinary involvement is rare with only one documented case from India. ${ }^{9}$

The life cycle of $C$. bezziana, from egg to egg under optimum conditions is about three weeks. Gravid females oviposit in batches of 150-3000 after getting attracted by odoriferous suppurating lesions or the eggs can be transferred into these sites by patients own fingers due to bad habits and poor hygienic conditions. The larvae are photophobic and penetrate deep into tissue aided by their sharp mouth hooks and anchoring inter segmental spines. The pathogenicity results from inflammation and toxin secreted by the larvae 


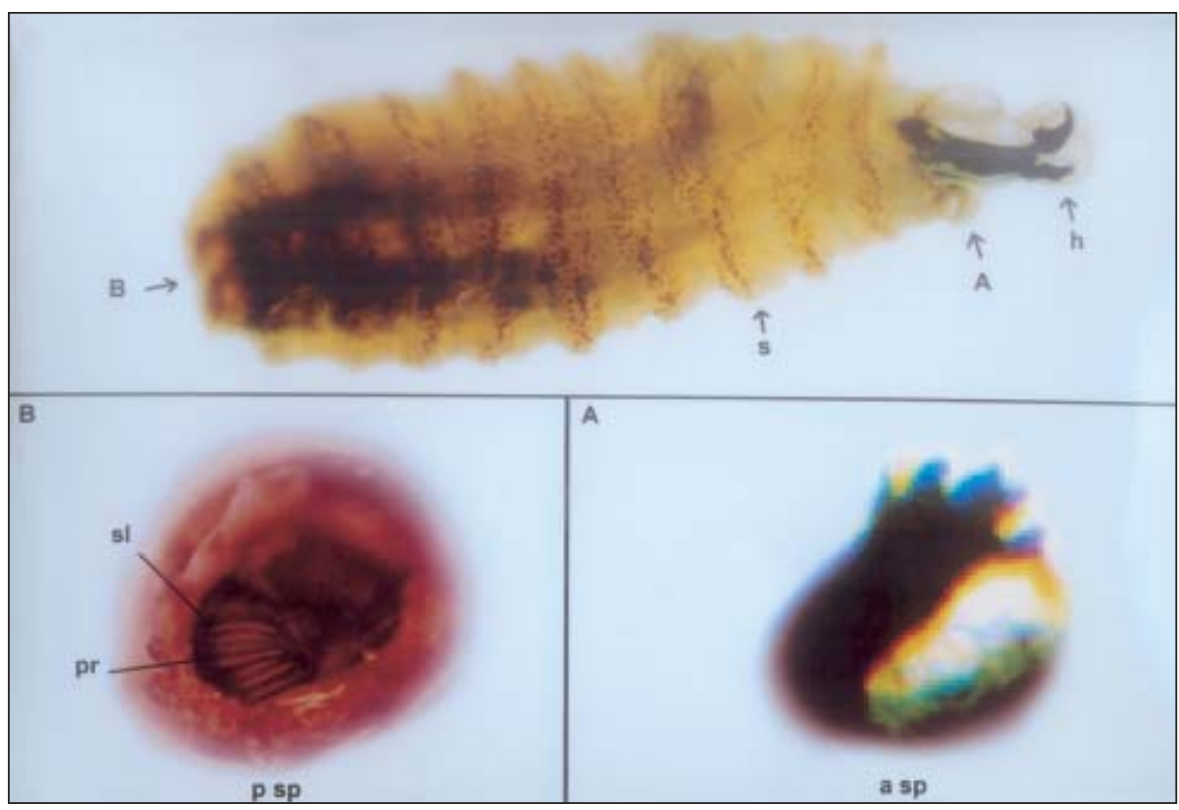

Figure: Photomicrograph showing larva of $C$. bezziana. Whole mount (ventral view) showing anterior hooks (h) and well developed annular bands of intersegmental spines (s) (x 20). The five finger like processes of anterior spiracle (a sp) are illustrated in A, while incomplete peritreme (pr), straight slits (sl) with lateral swelling of the posterior spiracle (p sp) is illustrated in B (x 40).

which prevents healing. ${ }^{8}$

The treatment is simple and involves usage of antilarval measures (terpentine oil or mixture of terpentine oil and chloroform) followed by the removal of the larvae. ${ }^{10} \mathrm{~A}$ broad antibiotic cover is recommended to prevent secondary infections.

Our case illustrates the importance of hygiene and sanitation in tropical countries with high fly population and emphasizes the need for correct diagnosis of this obligatory myiasis, which is potentially destructive.

\section{References}

1. Hyun DY, Cain MP, Blue-Hindy DE, Conway JH. Urinary myiasis associated with uretral stent placement. Pediatr Infect Dis J 2004:23:179-81.

2. Radhakrishnan R, Srinivasan R, Krishnamoorthy K, Sabesan S, Pani SP. Myiasis in filarial lymphedema due to Chrysomyia bezziana. Natl Med J India 1994;7:117-8.

3. Beaver PC, Jung RC, Cupp EW. Clinical Parasitology, $9^{\text {th }}$ edn.
Philadelphia: Lea \& Febiger; 1984. p. 680-94.

4. Meinhardt W. Urogenital myiasis caused by scuttle Flu larvae (Diptera:Phoridae). Br J Urol 1989;64:547-8.

5. Sachdev MS, Kumar H, Roop, Jain AK, Arora R, Dada VK. Destructive ocular myiasis in a non-compromised host. Indian J Opthal 1990;38:184-6.

6. Sreevatsa, Malaviya GN, Husain S, Girdhar A, Bhat HR, Girdhar BK. Preliminary observations on myiasis in leprosy patients. Lepr Rev 1990;61:375-8.

7. Verma L, Pakrasi S, Kumar A, Sachdev MS, Mandal AK. External opthalmomyiasis associated with herpes zoster opthalmicus. Can J Opthalmol 1990;25:42-3.

8. Kersten RC, Shoukrey NM, Tabara KF. Orbital myiasis. Opthalmology 1986;93:1228-32.

9. Menon S, Bharadwaj R, Rajput AG, Khare PM, Menon S, Bharadwaj R. Genital myiasis: Chrysomyia bezziana. Indian J Med Microbiol 1996;14 :213-4.

10. Singh I, Gathwala G, Yadav SP, Wig U. Ocular myiasis. Indian Pediatr 1991;28:1524-5. 